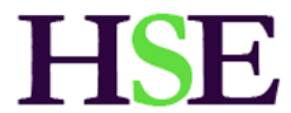

Historia Social y de la Educación

Social and Education History

Instructions for authors, subscriptions and further details:

http://hse.hipatiapress.com

\title{
La militarización de la educación física escolar. Análisis de dos imágenes publicadas en la prensa de Barcelona de principios del siglo $\mathrm{XX}$
}

Xavier Torrebadella Flix ${ }^{1}$

1) Universitat Autònoma de Barcelona

Date of publication: February $23^{\text {rd }}, 2017$

Edition period: February 2017 - June2017

To cite this article: Torrebadella, X. (2017). La militarización de la educación física escolar. Análisis de dos imágenes publicadas en la prensa de Barcelona de principios del siglo XX. Social and Education History, 6(1), 78-108. doi:10.17583/hse.2017.2393

To link this article: http://dx.doi.org/10.17583/hse.2017.2296

\section{PLEASE SCROLL DOWN FOR ARTICLE}

The terms and conditions of use are related to the Open Journal System and to Creative Commons Attribution License (CC-BY). 


\section{La Militarización de la Educación Física Escolar. Análisis de Dos Imágenes Publicadas en la Prensa de Barcelona de Principios del Siglo XX}

Xavier Torrebadella

Universitat Autònoma de Barcelona

(Spain)

\section{Resumen}

En los regímenes de escolarización de la infancia de principios del siglo XX, la educación física fue afín a medios y modos disciplinares de adoctrinamiento militar. La prensa gráfica de la época recogió imágenes que hoy nos testimonian la impronta de una militarización escolar susceptible de ser analizada desde la dialéctica-crítica y el "giro visual". A partir de dos imágenes, publicadas en el semanario La Hormiga de Oro de Barcelona, visualizamos las formas (re)productoras de violencia que subyacen en la educación física y desvelamos los dispositivos disciplinares (técnicas de saber/poder) que actúan en el inconsciente colectivo de la época para construir elementos de cohesión nacional.

Palabras clave: educación física, gimnástica militar, batallones infantiles, fútbol escolar 


\section{The Militarisation of Physical}

\section{Education in Schools. An Analysis of}

Two Images Published in the Barcelona Press at the Beginning of the Twentieth

\section{Century}

Xavier Torrebadella

Universitat Autònoma de Barcelona

(Spain)

\section{Abstract}

In infant schooling at the beginning of the twentieth century, physical education was similar to the disciplinary means and methods of military indoctrination. The picture press at the time printed images which show us today the mark of school militarisation which is open to analysis from a dialectical critical view and the "visual turn". From these two images, published in the weekly La Hormiga de Oro of Barcelona, the (re)productive forms of violence that underlie physical education become evident and the disciplinary devices (knowledge/power techniques) acting in the collective subconscious of the time for the construction of elements of national cohesion are revealed.

Keywords: physical education, military gymnastics, child battalions, school football 



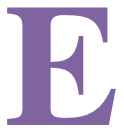

1 hacer historia de la educación utilizando materiales gráficos y documentos fotográficos como fuente principal (no verbal) y no auxiliar al texto, no suele ser habitual (Del Pozo, 2006; Sanchidrián, 2011). Son varias las autorías que han estudiado y argumentado las posibilidades del uso de las imágenes para alumbrar el discurso histórico en su propia realidad (Barthes, 1990; Benjamin, 1989; Burke, 2001; Burke, 2005; Gaskell, 1994; Huguet, 2002; Lara, 2005; Pantoja, 2007; Rodríguez de las Heras, 2009, 2010; Sanchidrián, 2011). Es precisamente desde esta posibilidad que surge en la historia de la educación un interés especial para poder utilizar los documentos fotográficos de los siglos XIX y XX como fuentes primarias y palmarias (Augustowsky, 2007; Burke y Grosvenor, 2007; Comas, 2010; Depaepe y Henkens, 2000; Del Pozo, 2006; Dussel, 2013; Lomas, 2011; Nóvoa, 2003; Sanchidrián, 2011; Vick, 2009; Viñao, 2005). Por otro lado, en España este tipo de estudios todavía se encuentran en un estado incipiente. Como cita Del Pozo (2006), aún queda mucho trabajo de base por hacer. Entre las primeras aportaciones conocidas, Julia Varela (1986) y Pilar Hinojosa (2003) prosiguen en la orientación iniciada por Philippe Ariès (1960) ocupándose de la infancia. Sin embargo, recientemente han aparecido algunas interesantes contribuciones (Collelldemont, 2014; De Freitas, 2015; Malheiro, 2015; Moreno Martínez, 2015; Sanchidrián, 2011). En cuanto a la historia de la educación física son muy pocos los trabajos conocidos que utilicen significativamente las imágenes (Comas, March y Sureda; 2010; Kirk, 2011; Rubio-Mayoral; 2009), a pesar del abundante y disperso material que existe en esta parcela de la educación.

Las imágenes son la congelación real de sucesos históricos (rastros y restos) $\mathrm{y}$, talmente, son portadoras de una carga substantiva para reinterpretar la profundidad social que encierran (Nóvoa, 2003; Viñao, 2005). Esta cuestión se hace necesaria en una sociedad democrática y, por lo tanto, posibilita el anudar las imágenes de la historia con la memoria y el salvar una educación contra el olvido (Lomas, 2011). Para Barthes (2015, p. 30), esta memoria es "el retorno de lo muerto" y una narración que confiere elementos tangibles a la historia. También, como cita Huguet (2002, p. 13), son generalmente las fotografías las que suelen reflejar "mejor que cualquier otro documento el cambio de la historia". 
Utilizar entonces, tal y como proponía Walter Benjamin, las imágenes para posibilitar deconstrucciones de la historia, "mostrando sus puntos ciegos, evidenciado su artificialidad" (Hernández-Navarro, 2011, p. 241), es una nueva manera de hacer historia, abierta (sin cerrar el tiempo), revisada y (re)contextualizada como material del presente, de un pasado que aún no ha pasado. Así percibe Benjamin (1989, p. 182) la memoria histórica, como la narración temporal del pasado que se descubre en el presente para pasarle "el cepillo a contrapelo", para hacer de la historia una política crítica y una dialéctica ingrata. En Benjamin, las imágenes tienen el poder de descubrir la historia incontable (del inconsciente), aportan materiales que pueden ser intemporales, manejados por el artista-historiador para desmitificar lo contado y hacer oposición política y discurso crítico al presente (HernándezNavarro, 2011). Por consiguiente, nos vamos a proveer del enfoque benjaminiano como cuña para abrir y desmitificar fragmentos de la historia de la educación física escolar; una historia de imágenes que empieza por apuntar a la cara oculta de la escuela (Fernández Enguita, 1990). Es por lo tanto, en esta cara oculta, que participamos del discurso de Raimundo Cuesta (2000, p. 29), cuando menciona que "las materias de enseñanza, en tanto que entidades históricas portadoras de funciones sociales implícitas y explícitas, contienen dispositivos de coacción y poder, de violencia simbólica y física, evocados en el propio vocablo 'disciplina". De aquí que el concepto 'disciplina' participe en los encajes entre el poder/saber, que a partir de la escolarización del siglo XIX se derivan en "ciertas pautas sociales y epistemológicas que están incluidas en las prácticas contemporáneas" (Popkewitz, 2000, p. 238).

Partiendo de estas premisas, y adoptando también un análisis desde la dialéctica-crítica (Zemelman, 2003ab) y el paradigma histórico genealógico sobre el poder que desarrolla Foucault $(2003,2012)$, introducimos el análisis de dos imágenes (de 1911 y 1913) en torno a la educación física escolar publicadas en el semanario La Hormiga de Oro de Barcelona: subtitulado "La ilustración católica" (1884-1936). A partir de estas imágenes construimos un discurso crítico en el que desvelamos los dispositivos disciplinares (técnicas de saber/poder), que emanan de la convención del poder militar y que actúan en la educación física. Visualizamos así, una disciplina que disciplina y que sujeta en el inconsciente colectivo de la época 
las ideas de modernidad, progreso y cohesión nacional: "orden social" y "paz civil".

\section{Metodología}

Siguiendo a Lara (2005), hemos establecido las siguientes pautas metodológicas:

a) Etiquetar un glosario de palabras clave bajo el nexo común temático de educación física escolar (gimnástica, gimnasia, deporte, educación física, batallón infantil, educación militar, foot-ball infantil).

b) Búsqueda de las imágenes realizada a través de la hemeroteca digital de la Biblioteca Nacional. Hemos buscado en las revistas ilustradas publicadas solamente en Barcelona, entre 1910 a 1914.

c) Recopilación de las fotografías mediante el nexo común temático, fragmentando la información visual, y analizando estrechamente la imagen y su conexión espacial y temporal (Rodríguez de las Heras, 2009, 2010).

d) Construcción de la narrativa crítica de las imágenes (textos visuales o lectura de las imágenes).

Obviamente se han considerado fuentes primarias en torno al fútbol (Barba, 1912; Elias, 1914; Gamper, 1914; Sanz, 1913), vinculas al objeto de estudio de una de las imágenes. Además, se han abordado otras fuentes secundarias de estudios sociales, relativas al momento histórico y conexas al contexto de estudio (Bembo, 1912; Brenan, 1962; De Bolòs y Vilanou, 2005; Del Pozo, 2002; Florensa, 1992; Jensen, 2014; Kirk, 2007; Masjuan, 2006, 2007). Para situar las imágenes en su contexto (particular y social), hemos revisado varios estudios en torno a la historia de la educación física en España (Bantulà, Bosom, Carranza \& Monés, 1997; Torrebadella, 2013, 2014abc; 2015ab).

Como hemos adelantado, abordamos el enfoque dialéctico de Walter Benjamin (1989), en busca de nuevos modos de narrar la historia (De Luelmo, 2007; Hernández-Navarro, 2011, 2012; Valdes, 2012). La "dialéctica de la imagen" que adoptamos es una dialéctica-crítica, que niega lo que realmente parece que es, para proceder al "giro visual". Así 
adoptamos la posición que permite apreciar a Boltanski (2014, p. 143), la "contradicción hermenéutica" del saber/poder institucional, con lo cual surge el dilema de negar la aceptación de "lo que ocurre con lo que es" (y ver lo contrario del que se dice y se hace). Esta posición también nos permite relacionar las proposiciones de Foucault $(2003,2012)$, investigar la historiasocial de la educación "desde el borde" o al margen de los determinismos y reduccionismos canonizados como métodos científicos (Torres, 2006). Esta visión crítica (y política) aborda problemáticas, no reconocidas, sobre los asuntos más escabrosos de la sociedad y que no interesan al poder políticocientífico. Desde esta posición dialectico-crítica podemos decir lo indecible, concienciar sobre lo desagradable y que nadie quiere visualizar, oír, decir y retener en la memoria. Así pues, desde la ruptura metodológica positivista, que surge del saber/poder dominante en las ciencias sociales, presentamos estas imágenes fotográficas portadoras de la invisibilidad retenida de códigos de violencia social, y que este saber/poder trata constantemente de borrar de la memoria colectiva de la historia (Torres, 2006).

Hemos tratado solamente dos imágenes públicas que ilustran dos caras diferentes de la educación física en el periodo indicado. Estas imágenes son de-codificadas y de-construidas a través de la narrativa visual, develando la gramática de los códigos disciplinares subyacentes que sirvieron para cimentar la educación física como asignatura. Por consiguiente, procedemos a un análisis comunicativo en el que la imagen se presenta como texto abierto y dinámico a diferentes visiones y significaciones que reconstruyen la historia de las fotografías. Pero también inferimos un análisis narrativo, por el que las imágenes son abordadas en el contexto histórico y desde la posición ideológica (dialéctica-crítica) como investigadores (Del Pozo, 2006). Además de la yuxtaposición de ambos análisis, contemplamos reforzar el discurso a través de la intertextualidad relacionada con otras imágenes y textos adscritos al mismo contexto.

Finalmente, como propone Del Pozo (2006), nos acomodamos al concepto iconotexto de Michael Nerlich (1990) (una historia poética aún no contada), pero lo hacemos desde "el giro visual", es decir: desvelando la intención oculta que se idea a partir de la intertextualidad y el discurso crítico. 


\section{Dos imágenes al descubierto: la deconstrucción de la gramática disciplinar de la educación física}

La Barcelona de principios del siglo XX y otras poblaciones próximas a su área de influencia representaron el nervio cardinal de la innovación cultural y del empuje industrial y económico del proceso de transformación social que se producía en España. En esta ciudad, el acelerado crecimiento urbanístico y productivo concentraba una populosa mano de obra proveniente de la Cataluña rural, pero también de otras regiones de España. Barcelona era reconocida por su poderosa sociedad burguesa que despilfarraba en excentricidades y ostentaciones culturales y recreativas de todo tipo (Permanyer, 2008), entre las que se destacaban las prácticas gimnástico-deportivas (Pujadas, 2012). Desde hacia varias décadas, en Barcelona se visibilizaba un importante desequilibrio social y división de clases. Si por un lado existía una pujante clase ociosa, que competía entre ella para el consumo y en el cúmulo de riquezas (Veblen, 2008), por el otro, crecía una significativa clase obrera inmersa en una lucha social por la supervivencia. En esta dialéctica social, la aparición de conflictos ideológicos politizados derivaron en brotes de violencia como la Semana Trágica, en 1909, o las huelgas generales de 1917 y 1919 (Porcel, 1978). Si la ciudad necesitaba todo tipo de servicios ociosos y de recreo para satisfacer las necesidades de las nuevas fortunas, no menos necesario eran otros servicios asistenciales, como aquellos destinados a la protección de la infancia desamparada (Sánchez-Valverde, 2009).

La concentración de la población obrera y marginal en el entorno urbano alimentaba todo tipo de escenas de corrupción o degeneración social (alcoholismo, prostitución, delincuencia callejera, mendicidad, corrupción infantil, invertidos, etc.) que estigmatizaba la visibilidad de la vida cotidiana (Bembo, 1912). Las preocupaciones (o miedos) a las enfermedades sociales y a la degeneración (Campos, 1998) afectaban a las clases acomodadas (o gente respetable), que necesitaban distanciarse de este entorno considerado depravado y peligroso, muy afectado por la insalubridad, las enfermedades contagiosas (sífilis, tifus, cólera...), la tuberculosis y una miseria generalizada (Calvo, 2012; Sánchez-Valverde, 2009).

Como describía hacia 1915 el doctor Domènech Martí y Julia (18611917), presidente de la Unió Catalanista, la vida de la clase obrera era extremadamente miserable (Martí, 1984). Ante esta situación, las clases 
dirigentes emprendían políticas de dominación capitalista actuando sobre el orden social y el saneamiento moral del obrero (Calvo, 2012). No obstante, los conflictos asociados a la lucha obrera afloraron en movimientos anticlericales, antimilitaristas y anarquistas, que también impregnaron el sentir ideológico de la educación (Aisa, 2015; Saladrigas, 1973; Turin, 1967).

Por lo tanto, es en esta coyuntura, que las tecnologías hacia el control bio-político fueron encaminadas a un proceso de oportunas soluciones pacificadoras (civilizadoras) en torno a la medicina social, la militarización de la clase obrera, la escolarización de la infancia, el encierro hospitalario (centros de tuberculosos) y las colonias fabriles. Como trata Foucault (2012, p. 160), estos eran los nuevos espacios de la sociedad disciplinada en la que se fabricaban los "cuerpos sometidos y ejercitados, cuerpos "dóciles", para su explotación social y lucrativa. Entre estas soluciones pacificadoras, participando muy significativamente en la modelación las corporalidades, también surgió la disciplina de la gimnástica y el deporte, y su encierro en el gimnasio y en los campos de juego (Kirk, 2007).

A propósito de este tipo de encarcelamientos, en estos tiempos se propagaron los grandes colegios religiosos (jesuitas, escolapios, hermanos de las Escuelas Cristianas, hermanos Maristas) que, destinados a educar a los hijos de las clases pudientes, en algunos aspectos, trataban de encarnar su equivalente a las Publich schools de Inglaterra. Por ello, estos colegios fueron ubicados en magníficos edificios con zonas verdes y campos de juego espaciosos, con todo tipo de equipamientos y los mejores maestros y especialistas (Bantulà, Bosom, Carranza \& Monés, 1997). Esta condición hizo de estos colegios que se erigieran como los verdaderos pioneros del deporte escolar.

\section{La imagen 1. Sección del Batallón infantil de los padres escolapios de Sabadell}

Después de la Guerra Franco-Prusiana, los Estados-nación de Europa se apropiaron de las ideas de Clausewitz (1984) y realizaron un cambio estratégico en sus políticas: la guerra venía a ser la continuación de la política con otros medios. La instauración de los batallones escolares franceses y su extensión meridional formaba parte de este nuevo giro 
político. Fue entonces cuando el ejército español se fijo en los modos de formación militar prusianos. Las ideas de Clausewitz ilustraban un cambio ideológico en las estructuras directivas del ejército, el cual pasaba por tomar un nuevo objetivo: el nacionalizar (militarizar) a toda la ciudadanía (Jensen, 2015). En fervor a esta nueva política se pronunciaban discursos ideológicos con el objeto de incorporar la instrucción militar a la escuela (Torrebadella, 2015b). De aquí surgieron, durante la última década del siglo XIX, los primeros batallones infantiles (escolares), pero es precisamente a raíz de la crisis finisecular (pérdidas coloniales) que se intensificó su aparición por todo el territorio. Coincidiendo con la guerra de Marruecos (1909-1927), estas organizaciones fueron nuevamente reconducidas con la recepción de los Boy-Scouts, que adoptaron el nombre de Exploradores de España (Torrebadella, 2013, 2015b). El encaje de la omnipresencia militar se materializó en acreditadas y públicas voces civiles, como la de Federico Climent (1912, p. 6), que no dejaba de advertir sobre la trascendencia de la educación militar: "la educación militar en las escuelas, como modalidad subalterna de la educación física en general, puede influir muy eficazmente".

María del Mar del Pozo (2000) identifica en estos pequeños soldadoscristianos, la intención política de conformar un ideal nacional común, para mantener el orden establecido fundamentado en la disciplina y la obediencia. Se trataba, por lo tanto, de una invención del regeneracionismo católico y militar, que se mostraba como solución para salvar España. La presencia del ejército invadía por completo las escenas de la vida social y las escuelas se convirtieron en los dominios de una cultura militarizada (Torrebadella, 2016c). 


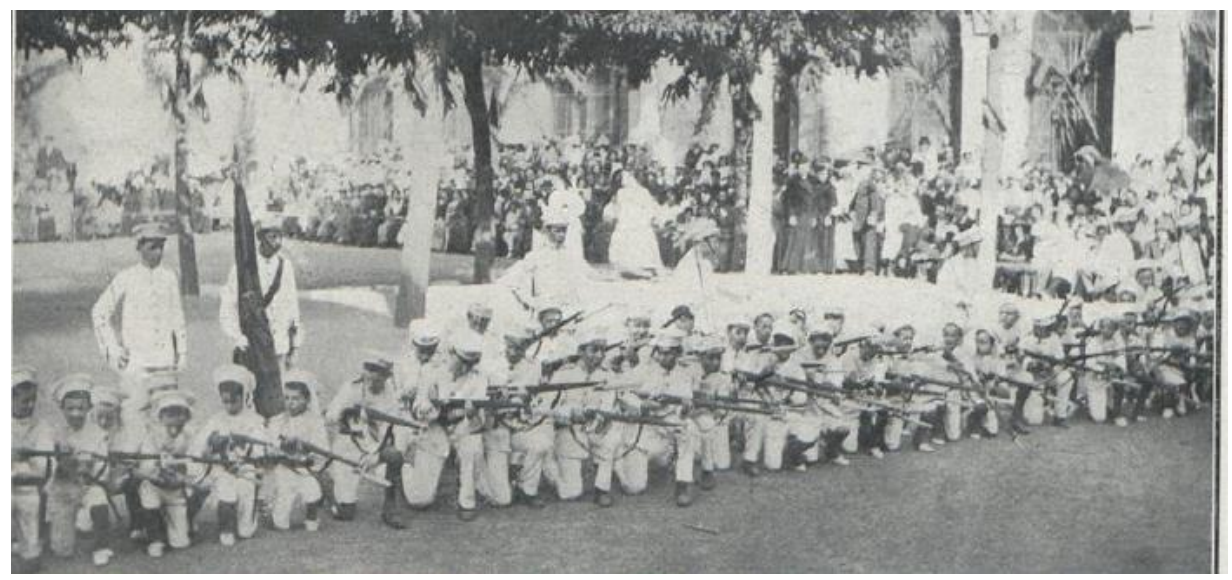

Imagen 1. La Hormiga de Oro (14 de junio de 1913, p. 12) Pie de Foto: "Sabadell.Una sección del Batallón Infantil antes de disparar los fusiles”.

La imagen 1 es una sección del Batallón Infantil del colegio de los padres escolapios de Sabadell, en el Festival de Educación Física de 1913, celebrado en el patio interior del mismo colegio. En este colegio se reunían los hijos varones de las mejores familias de la ciudad (Torrebadella, 2014a). Sabadell concentraba entonces una pujante industria textil impulsada por una burguesía conservadora y católica (integrista). La industria sabadellesa se enriqueció durante el transcurso de la I Guerra Mundial fabricando mantas y uniformes militares para los aliados (Deu, 1990). Como es lógico, también existía una importante concentración obrera que se manifestaba culturalmente en un conglomerado de asociaciones de signo anticlerical, antimilitarista y racionalista (Masjuan, 2006). Por otro lado, un dato a destacar es el importante núcleo anarquista que acogía. Sabadell es la ciudad de Mateo Morral, el empresario y culto anarquista que atentó contra el cortejo nupcial de Alfonso XIII y Victoria Eugenia, el 31 de mayo de 1906 (Masjuan, 2009).

Se trata de un grupo de jóvenes (unos treinta y cinco), entre 7 y 9 años, perfectamente uniformados de oficiales del ejército. Son unos uniformes elegantes de color blanco (uniformes de la Marina), símbolo aristocrático y también de pulcritud, seguramente confeccionados por la industria textil de 
la localidad. Los niños están preparados en posición de rodilla al suelo, en disposición de disparar con sus fusiles tipo Máuser y con las bayonetas caladas. Detrás están sus instructores oficiales, con sable en mano, dirigiendo atentamente la actividad; uno de ellos portando la bandera. Se trata de una situación que bien pudiera representar un fusilamiento. En el fondo, a la derecha, los padres escolapios, junto a unos oficiales militares y las familias, examinan atentamente la exhibición del Festival de Educación Física. No podemos apreciar el rostro de los espectadores, pero ante la frivolidad aterradora del momento, cierto miedo oculto seguramente apresa el pensamiento de algunos. También se divisan entre los espectadores, elementos de las fuerzas vivas de la ciudad. Los alumnos están listos para disparar a un objetivo (supuestamente imaginado); es otro objetivo, que también, como la máquina de fotografiar, captará la última instantánea de una vida que se desvanece en decimas de segundo.

La imagen es un cruce de miradas. Los espectadores miran la exhibición del batallón infantil, éste mira a un objetivo que no podemos ver (puede que imaginario), que también puede que mire. No obstante, la mirada más poderosa es la del objetivo del fotógrafo, que nadie mira mientras captura toda la escena que inmortaliza. Es el fotógrafo el que dispara a todos y los in-mortaliza. Pero esta imagen no está aislada, tiene otras imágenes previas y posteriores, que también encajan en una combinación de fragmentos de sucesos y de diferentes escenarios con los que podemos construir una asociación (Rodríguez de las Heras, 2009, 2010). Revisando la prensa y otros documentos hemos encontrado otros fragmentos de la imagen y otras imágenes distanciadas en el tiempo de la primera, pero que posibilitan el conocer procesos significativos. Así se aprecian otras imágenes de los pequeños soldados desfilando por las calles de la ciudad, en el patio del colegio en solemne bendición de la bandera $\mathrm{y}$, luego, ejercitando movimientos de armas. El batallón infantil del colegio de los escolapios de Sabadell fue constituido y presentado en 1912, públicamente apadrinado por Joaquín Bamboe, el Sr. Victoriano Uejido y el hijo de este, capitán de la Guardia civil (Editorial, 1912). Los festivales de educación física de los escolapios de Sabadell fueron publicitados en la elitista prensa gráfica. Ello indica el poder (económico y político) que tenía esta institución colegial, que además representaba el de las familias de estos niños. Este batallón infantil también se realizó fotos de estudio que convirtió en postales (Masjuan, 
2006). En 1917 este batallón ya había desaparecido, pero se habían constituido otras formaciones sucedáneas como los Exploradores de España Boy-Scouts. De aquí que Miguel de Unamuno (1917, p. 6) criticase la falta "juego limpio", puesto que la nueva institución continuaba preservando las mismas intenciones que antes.

Por otro lado, la escena de la imagen tiene una narrativa mucho más profunda de la que parece. En ella se desvela la nacionalización de la infancia. Se presentan unos niños que son preparados para la muerte, para cuando llegue el día, si la patria los necesitara, defenderla hasta con su vida. Este día, para algunos no tardaría, puesto que en 1936 ya estaban instruidos para ello: ¿Cuantos de estos niños murieron empuñando las armas? Sin embargo, para los jóvenes de esta época, la guerra no era una cosa extraña. España estaba en guerra y, en poco tiempo, el mundo entero también lo estaría. Imágenes similares eran exhibidas en la prensa gráfica nacional. Son imágenes públicas que normalizan una situación y proyectan un discurso social. Los batallones escolares estaban amparados por las fuerzas vivas: los militares, el clero, los dirigentes políticos y la llamada "buena sociedad". Sin embargo, la pregunta crucial que debemos hacernos es: ¿A quien disparan? ¿Quién es el enemigo? ¿Son los rifeños, los anarquistas, los separatistas,...?

Con estas peguntas, vamos seguidamente a ver la contradicción hermenéutica de la imagen y su giro visual. Como trata Foucault (2012), en los regímenes de la escolarización se definen los códigos disciplinares militares que han encontrado refugio en la colonización de la corporalidad de la infancia. Ello se consigue a través de procedimientos instructivos, inoculados por el adoctrinamiento disciplinario y la obediencia a la autoridad. La ejercitación de la gimnástica militar cumple perfectamente este cometido. La escuela se ha convertido en cuartel. Sin embargo, estos niños que juegan a la guerra, por lo que son y representan, no son los que van a ir a la guerra. Ellos, pueden pagar la cuota que los libra de su obligación. Los que van a ir a la guerra son las almas invisibles a la foto (los ausentes); los niños que en este momento rondan las calles descalzos o están trabajando en la fábrica. Esto ocurría en una ciudad como Sabadell, cuya concentración obrera acogía a numerosos niños y niñas que se veían forzados a trabajar (es)forzadamente hasta diez horas diarias como si fueran adultos, en unas condiciones higiénicas lamentables de trabajo y recibiendo todo tipo de abusos físicos y morales (Masjuan, 2006). Las clases subalternas no 
visionaban del mismo modo los panegíricos militaristas, sufrían la guerra en sus propias carnes y eran anti-militaristas. Como trata Masjuan (2006, p. 77), veían en estas pomposas manifestaciones de los batallones infantiles un "escarnio cultural y una profanación de la escuela". Reconocían que la guerra era una invención cultural. Las voces discrepantes se hacían sentir y, en la prensa antípoda, se hablaba de los padres escolapios como los "mercaderes de enseñanza que vienen a inculcar el odio de la razas y la guerra. La guerra que es el atentado más grande contra la civilización que nosotros soñamos acto de incivilidad" (Masjuan, 2006, p. 77).

En Sabadell, sin embargo, había quien se manifestaba por una pedagogía crítica y una educación física crítica (Torrebadella, 2016a). Ciertamente, como se mencionaba en el periódico Sabadell Federal, se producía un "triste espectáculo", al reemplazar la educación física de verdad, por juegos de "simular batallas, en tomar trincheras, en asaltar pueblos".

También el ejército venía a constituirse como el baluarte de una conciencia nacionalizadora, que al amparo de la monarquía defendía la unidad territorial y garantizaba, manu militari, el orden y la paz social (Cardona, 1983). En una Cataluña antimilitarista y de aspiraciones soberanistas, el ejército se presentaba como "el más fanático enemigo del nacionalismo catalán” (Brenan, 1962, p. 27) y, por añadidura, los discursos de la iglesia y la burguesía católica reaccionaria aprobaban las represiones y las violencias hacia la clase obrera (Moliner, 2000); utilizando, a propósito, demostraciones de fuerza que se manifiestan a través de los círculos paramilitares de las Juventudes Carlistas y Requés (González Calleja, 1998). Paradigma de esta situación fueron los sucesos en torno a la citada revuelta popular de 1909 (Semana Trágica), momento en el que se acrecentaron los miedos de las clases dirigentes. De aquí que la iglesia y las clases ricas buscasen protección en el poder militar, en la corona y en las políticas más conservadoras (Ucelay-Da Cal, 2003). Esta situación constituía un claro enfrentamiento social que trascendía en la ideologización política de las clases subalternas (proletarias y populares), las cuales se adentraban en un proceso de descristianización, de antimilitarismo y sindicación obrera de signo anarquista (Porcel, 1978).

Estos son algunos de los posibles títulos (iconotextos) que, a guisa de crítica social, podríamos poner a pie de imagen: "Batallón de fusilamiento", "Jugando a la guerra", "Los niños que se salvaran de ir a la guerra", 
"Obedezcan y disparen", "Disparando al enemigo", "Soldaditos inocentes", "Educados para matar", "Los defensores de la Patria", "Muertes anunciadas", "El miedo va por dentro", "Por qué me enseñan ha ser soldado, si no quiero ir a la guerra", "Por qué tengo que jugar con las armas, si a mí me gustan las muñecas?

\section{La imagen 2. Sporting Club estudiantil del Colegio de Calasancio de las escuelas pías de Barcelona}

En España el deporte en edad escolar inició su institucionalización hacia los primeros años del siglo pasado. Su presencia fue empujada por la coyuntura internacional de expansión del deporte, pero también vino a satisfacer los intereses quiméricos de una metáfora modernista y de progreso (Torrebadella, 2012, 2014c). En esta época el fútbol, para algunos citado balompié, se remozaba de un discurso regeneracionista y su domino moraba en la selecta burguesía que lo prácticaba (Torrebadella-Flix y NomdedeuRull, 2013). En el terreno educativo, el fútbol satisfacía la expresión más genuina de la visión arnoldiana del christian gentleman, que fue asumida, tanto por los colegios religiosos, como por las escuelas laicas de la Institución Libre de Enseñanza (De Bolòs y Vilanou, 2005).

En Barcelona, principal enclave en la promoción del fútbol en España (Torrebadella, 2012), los equipos constituidos en los colegios más prestigiosos se convirtieron en la cantera de los primeros clubs de la ciudad; prueba de ello es la organización en 1910 del primer Campeonato de Cataluña de Fútbol Infantil (Torrebadella-Flix y Nomdedeu-Rull, 2015). Detrás del fútbol escolar se encontraban voces como la de Hans Gamper (1911, p. 1), el cual valoraba el fútbol como un importante elemento pedagógico y de cultura física y, "sin disputa alguna, el mejor y mas completo de los deportes". El fútbol se convertía entonces en el nuevo juego de moda y substituía a otros tan tradicionales como el del "marro". No obstante, ambos juegos representan una escena fingida de la guerra para formar el carácter agonístico de los jóvenes (Brasó y Torrebadella, 2015ab).

El nuevo deporte del balón disponía de toda la autorización pedagógica y era aconsejado por sus características físicas y morales, pero sobre todo ensalzado por el carácter disciplinar que proporciona (Climent, 1906; Barba, 1912; Elias, 1914; Gamper, 1911; Graham, 1913). Esta disciplina se muestra 
en la obediencia absoluta hacia el capitán del equipo. El fútbol es esfuerzo, sacrificio, resistencia, fuerza,... y se convierte en una disciplina que disciplina que proporciona el dominio de sí mismo (Self-government) (Almeida, 2003). Pero además, el fútbol también era visionado como un poderoso medio coercitivo en las aventuras de la sexualidad, como así lo mencionaba el principal artífice de este deporte en Barcelona: El fútbol aparta a "la juventud de la creciente vorágine de las pasiones, a que predispone la vida agitada y agobiosa de las grandes urbes modernas" (Gamper, 1914, p. 13).

Pero no nos engañemos, el fútbol de entonces era muy rudo y violento, prácticamente se jugaba sin conocimiento del reglamento y sin preparación física y técnica. Esto comportaba un juego a cañonazos o pelotazos, con todo tipo de puntapiés, golpes y cargas al contrario. Las disputas por el balón se convertían en verdaderos campos de batalla (Torrebadella-Flix y Nomdedeu-Rull, 2015). De aquí surgían los consejos a los jóvenes, de prepararse físicamente antes de practicar este violento deporte (Sanz, 1913). Dadas estas características del juego, se apreciaba en el fútbol un vigoroso ejercicio atlético y viril, perfectamente adecuado para la preparación militar y patriótica (Barba, 1912).

José Elias (1907, 11), el apóstol del olimpismo catalán, también vinculaba la educación física y el deporte a la seducción luchadora: "Si la vida es una lucha, hay que luchar, y en último término vencer: he aquí nuestro ideal”. Así se entiende que Elias (1911, p. 29) tomase los “deportes para regenerar nuestra raza y ponerla al nivel de las más fuertes del mundo, para poder luchar con ellas en todos los terrenos de la actividad humana". También eran elocuentes las retoricas utilizadas, en alusiones a la Guerra franco-prusiana, para enardecer el patriotismo:

Recordar la gran epopeya del imperio, la guerra del 70, después de la cual el gran Bismark decía delante de los maestros alemanes:Vosotros habéis ganado la guerra, haciendo ciudadanos fuertes y valientes, gracias a los sports enseñados a los escolares, $-\mathrm{y}$ mucho más tener presente las enseñanzas de aquella lucha, cuando el general Molke afirmaba por otra parte, que la educación integral del pueblo alemán y no las armas le habían dado la victoria. (Elias, 1913, p. 3) 
Elias es también conocido por publicar Foot-ball asociación (1914), el primer libro monográfico del fútbol español (Torrebadella-Flix y Nomdedeu-Rull, 2015). En él aparecía este deporte como el mejor medio de educación física de la juventud y se idealizaba como "el medio más eficaz para la regeneración de nuestra raza" (Elias, 1914, p. 19). Este sportsmen barcelonés mencionaba que en el fútbol se encontraba el "origen de la supremacía actual de los británicos, nacida de la revolución que en los sistemas de enseñanza introdujo el gran Thomas Arnold" (Elias, 1914, p. 25).

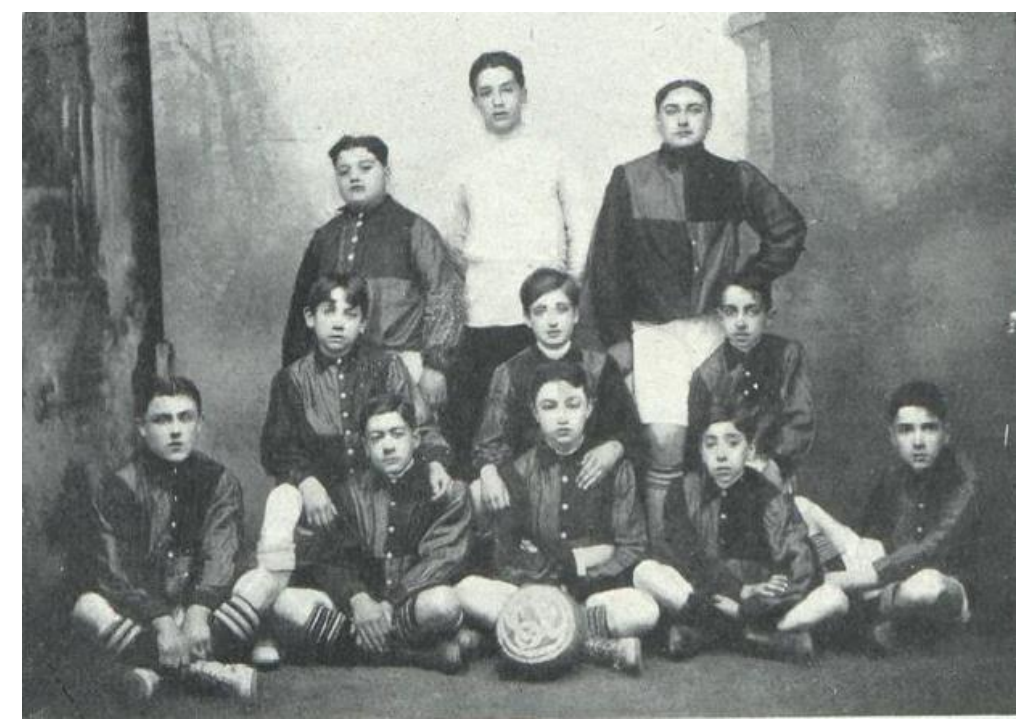

Imagen 2. La Hormiga de Oro (13 de mayo de 1911, p. 301). Pie de Foto: "De "foot-ball". Primer "team" del "Sporting Club Estudiantil" establecido en Colegio Calasancio de Barcelona".

En la imagen 2 se muestran públicamente los alumnos del primer team Sporting Club Estudiantil del Colegio de Calasancio de las escuelas pías de Barcelona -Colegio de San Antón- (Florensa, 1992). Posan con elegantes vestidos deportivos (seguramente colores encarnado y azul), en la perfecta y clásica alineación futbolística de la época (un portero, dos defensas, tres 


\section{Torrebadella - Militarización de la Educación Física Escolar}

medios y cinco delanteros). Se trata de una foto de estudio, su coste es elevado y solo está alcance de las clases acomodadas. En el centro está su propio balón oficial; es un elemento recreativo de lujo y no está al alcance de la mayoría de las familias. En aquella época un balón valía entre 18 y 20 pesetas (Anuncio: El Mundo Deportivo, 16 de mayo de 1912, p. 4); un precio que contrastaba mucho, cuando el sueldo medio semanal de un obrero podía rondar las 3, 25 pesetas (Soto, 1989).

Es de suponer que la foto surge de la propia voluntad de los muchachos. Es una decisión que toman ellos con el objeto implícito que contiene la foto de estudio: la de eternizar un momento para el recuerdo. Se trata probablemente del primer equipo de fútbol de su vida. La foto representa un acontecimiento importante al ser la primera asociación (empresa) o proyecto compartido, lo cual tiene para los jóvenes un singular valor simbólico. Todavía es más el valor que seguramente tenía para sus tutores, que podían ver, en una concepción arnoldiana, un significativo ejemplo educativo de preparación para la vida (Ferrer, 2012): "Una asociación deportiva es una sociedad en pequeño: un equipo de balompié, un diminuto ejército" (Valserra, 1944, p. 247).

Este tipo de foto es muy característica en los equipos de la época, que siempre aparecen con la misma posición de alineación. En la foto solamente se muestran once jugadores, no sabemos si falta el resto del equipo (los reservas). La alineación representa la disciplina del fútbol de la época. Uno de ellos debe ser el capitán. En el terreno de juego, cada jugador tiene su posición, que debe asegurar y no debe perder bajo ningún pretexto. Todos los jugadores se comprometen a la obediencia del capitán, que es quien dirige el juego. Esta alineación también simboliza el orden y la norma que se establece en la sociedad, en la que cada individuo tiene un puesto asignado.

Posiblemente por la mente de estos jóvenes se recreaba el sueño de llegar a ser algún día uno de los populares futbolistas, como los que nutrían los grandes equipos que existían en Barcelona.

En la contradicción hermenéutica y el giro visual, apreciamos como esta imagen puede reducirse hasta encontrar los signos de una arcaica estructura masculina engendrada desde la violencia. Los once jugadores de fútbol son la antigua decuria romana, diez soldados con su decurión (el capitán); la misma organización, como cita Foucault (2012), que fue adoptada en los 


\section{HSE - Social and Education History, 5(1)95}

colegios jesuitas para acrecentar la obediencia y competitividad entre los alumnos:

Cada uno de estos grupos, con su decurión, estaba colocado en un campo, el romano o el cartaginés; a cada decuria le correspondía una decuria contraria. La forma general era la de la guerra y la rivalidad; el trabajo, el aprendizaje, la clasificación se efectuaban bajo la forma de torneo, por medio de enfrentamiento de los dos ejércitos; la prestación de cada alumno estaba inscrita en ese duelo general; aseguraba por su parte la victoria o las derrotas de un campo y a los alumnos se les asignaba un lugar que correspondía a la función de cada uno y a su valor como combatiente en el grupo unitario de su decuria. (Foucault, 2012, p. 169)

Dicha organización es también la que más tarde adoptó Thomas Arnold en el colegio de Rugby instalando su particular sistema de prefectos, el cual "fue vital para el desarrollo inicial del foot-ball" en Inglaterra (Dunning, 2003, p. 112).

Por lo tanto, como cita Miguel Vicente (2004), no podemos hablar de la construcción social del deporte y de nuestros cuerpos sin conocer y valorar su impacto histórico en el proceso de los regímenes escolares de la infancia y la adolescencia.

El deporte escolar o infantil es la base de la pirámide deportiva contemporánea y blanco económico de capitalismo neoliberal. Desde hace decenios, la educación de la infancia es estimulada a través de dispositivos disciplinarios de carácter competitivo. La mayoría de los juegos corporales suelen tener una componente agonística simbólica importante, que opera como dispositivo y determina conductas. El poder simbólico del deporte escolar, siguiendo a Bourdieu (2001), se presenta como un poder invisible que se cultiva con la complicidad de todos, tanto los que lo sufren como los que lo ejercen. Se trata aquí de la ficción de los manipulados valores del deporte, o de "las beaticas virtudes moralizadoras y normalizadoras" (Vicente, 2010, p. 83). Unos valores, que constituidos bajo el mito del deporte educativo, construyen subjetividades y manipulan conciencias colectivas. Tanto es así, que hoy asistimos a una educación física deportivizada (a una escuela deportivizada y una sociedad deportivizada), en 


\section{Torrebadella - Militarización de la Educación Física Escolar}

donde el deporte ha determinado, en gran parte, la ideología docente de la materia.

Es a partir de 1919, tras la experiencia de la Gran Guerra, cuando el deporte se reinventa políticamente y entra en la esfera de las contiendas nacionales (Torrebadella, 2016a). En palabras Hobsbawm (2000, p. 152), el deporte "se transformó en una inacabable sucesión de encuentros de gladiadores protagonizados por personas y equipos que simbolizan estadosnación, lo cual forma hoy día parte de la vida mundial". A partir de entonces fue cuando en el ejército español movilizó las prácticas deportivas y en especial la del fútbol, que se presentaba como el mejor deporte de preparación para la guerra (Torrebadella-Flix y Olivera-Betrán, 2016).

El deporte se encuadra perfectamente en la proposición de Clausewitz (1984, p. 58): "la guerra es la mera continuación de la política por otros medios". Así, y partiendo de la inversión de esta proposición que hace Foucault (2003, p. 24): "la política es la continuación de la guerra por otros medios", por lo que declaramos su continuidad admitiendo, que es lo mismo que decir, que el deporte no es más que una política de "guerra", con otros medios. Y siguiendo la tesis de Foucault (2003, p. 24), si el "poder es la guerra, es la guerra proseguida por otros medios", también es admisible citar que el deporte es un poder (político y de guerra) proseguido con otros medios. Guerra, política, deporte y poder entran de pleno en el paradigma del proceso civilizador de Norbert Elias (2010). El deporte es entonces un poder, un militarismo invisible; "una especie de guerra silenciosa" (Foucault, 2003, p. 25), que también llega hasta nuestros días; es una sociabilización de la violencia o un juego, "que instruyen a los niños en una cultura sádica donde el matar está bien" (Giroux, 2013, p. 69).

Benjamin (2001, p. 29) percibía el militarismo como "el impulso de utilizar de forma generalizada la violencia como medio para los fines del Estado". Con este enfoque benjamniano, podemos ver en muchas imágenes del deporte la sociabilización inconsciente de la guerra. El deporte serio, como citaba George Orwell, tras ver en 1945 unos partidos de fútbol entre el Dynamo de Moscú y equipos ingleses: "Esta relacionado con el odio, celos, jactancia, desprecio de todas las reglas y placer sádico en contemplar la violencia: en otras palabras es una guerra sin disparos" (Pritchard, 2015, p. 77). El fútbol es la genuina metáfora de la guerra y, desde sus ancestros, la esencia no ha cambiado. No existe un fútbol (deporte) civilizado y no tiene 
que ver nada con la invención del fair-play. El deporte civilizado es un mito, una construcción burguesa presa hoy del neoliberalismo más depredador y de la barbarie deportiva (Perelman, 2014, p. 192).

Iconotexto para el pie de la imagen: "Un recuerdo para la posteridad", "A las ordenes mi capitán", "Dispuestos para el combate", "Esperando al enemigo", "Los nuevos gladiadores", "La decuria romana".

\section{Conclusiones}

Las imágenes aquí presentadas desvelan lo connatural de la época, las formas consentidas y civilizadas de educar la violencia en los regímenes disciplinarios de la escolaridad. Ambas fotografías capturan lo invisible: los dispositivos de la masculinidad, la crueldad, la dominación, las desigualdades y la opresión; modos de una obediencia y disciplina, el clasismo de un poder social que ordena y vigila que todo permanezca como se ha concebido y que nada altere el orden. Se trata de una educación que debe conceptuarse en la coyuntura clasista y los subterfugios que utilizan la éites para construir divisiones y distancias sobre la población subalterna.

Tanto los batallones infantiles como el fútbol conformaron el conjunto de prácticas físicas de dominación de la época (Exploradores de España, gimnasia sueca, Festivales gimnásticos y otros deportes que también pertenecen a este campo). Ambas prácticas fueron dispositivos socializados e institucionalizados, pensados para el buen encauzamiento de la juventud y la militarización social. Pero estos jóvenes de las fotografías no eran los escogidos para ir a la guerra, paradójicamente fueron los más débiles, que también eran los más pobres. Los niños sanos, robustos y cultivados jugaban a la guerra con sus armas de juguete o con el balón. En cambio, los niños enfermizos, débiles y sin estudios trabajaban como adultos en la industria fabril. No es nada extraño, que este clasismo visionado por la infancia en peligro y peligrosa engendrase odio y violencias simbólicas hacia los niños de papa.

Por otro lado, el poder disciplinario de la educación física, el de los batallones infantiles y el del fútbol, cooperaron también en el cúmulo de los dispositivos biopolíticos utilizados para acrecentar la masculinidad, la cohesión social, la "españolización” y para impostar una idealización del Estado-nacional. En este constructo subyacía el implícito acuerdo de los 
intereses (políticos y económicos) entre el poder militar, la monarquía, la iglesia y las clases acomodadas.

Finalmente visualizar que estas formas pretéritas de educación física (batallones infantiles y fútbol "a cañonazos"), hoy nos darían escalofríos. También destacar aquí, que en la educación en general, y especialmente en la educación física, el proceso de civilización de Elias (2010) se ha hecho palmario, pero con ello no debemos pensar que hayan desaparecido los modos de ejercer el saber/poder y el de otras formas, aparentemente no violentas, de una militarización simbólica de la infancia y la juventud.

Recuperar estas imágenes para (re)historiar la educación del siglo XX es contribuir a la memoria del presente y reformular una nueva historia de aquellas sombras que la oficialidad a negado a la colectividad. Dar voz a las imágenes es hacer visibles las invisibilidades de un pasado políticamente silenciado.

A través de este estudio hemos adelantado en la preservación de la memoria histórica individual y colectiva de la educación física. Reconocemos que no son habituales los análisis que se adentren en los arriesgados giros de-constructivos de las imágenes, es por eso que esperamos que la presente aportación estimule este tipo de enfoques.

Para terminar, solamente nos queda por añadir que ya han desaparecido las embarazosas barreras que hace apenas unos años privaban el acceso a las imágenes. Hoy el uso de las imágenes es toda una posibilidad con la infinidad de repositorios y hemerotecas con fondos digitalizados y, por eso, ya es más fácil iniciar la recuperación de una memoria visual de la educación física escolar. En adelante, el localizar, registrar e indizar las imágenes históricas, con el objetivo de su inmediato uso para estudiarlas y valorarlas, puede ser una tarea muy estimulante.

\section{Notas}

${ }^{1}$ Sabadell Federal, 30 de mayo de 1914 y 15 de junio de 1915. (fragmentos traducidos del catalán) 


\section{Referencias}

Aisa. F. (2015). La cultura anarquista a Catalunya. Barcelona: Edicions de 1984.

Almeida, A. S. (2003). Les "Public Schools" i la reforma educativa de Thomas Arnold (1828-1842). Temps d'Educació, 27, 305-329.

Recuperado de http://www.raco.cat/index.php/TempsEducacio/article/view/126391

Ariès, Ph. (1960). L'enfant et la vie familiale sous l'ancien régime. Paris: Plon.

Augustowsky, G. (2007). El registro fotográfico en la investigación educativa. I. Sverdlick (Comp.), La Investigación educativa: Una herramienta de conocimiento y de acción (pp. 147-177). Buenos Aires: Novedades Educativas.

Bantulà, J., Bosom, N., Carranza, M., \& Monés, J. (1997). Passat i present de l'educació física a Barcelona. Barcelona: Ajuntament de Barcelona.

Barba, A. (ca. 1912). Football, basse ball y lawn tennis. Barcelona: Ed. Sucesores de M. Soler.

Barthes, R. (2015). La cámara lúcida. Barcelona: Paidós.

Bembo, M. (1912). La mala vida en Barcelona. Barcelona: Maucci.

Benjamin, W. (1989). Discursos interrumpidos I. Buenos Aires: Taurus.

Benjamin, W. (2001). Para una crítica de la violencia y otros ensayos.

Madrid: Taurus.

Boltanski, L. (2014). De la crítica. Compendio de sociología de la emancipación. Madrid: Akal.

Bourdieu, P. (2001). Poder, derecho y clases sociales. Bilbao: Desclée. Brasó, J., y Torrebadella, X. (2015a). "El marro", un juego tradicional y popular en la educación física española (1807-1936). Revista Complutense de Educación, 26(3), 697-719. Recuperado de http://revistas.ucm.es/index.php/RCED/article/view/44680

Brasó, J., y Torrebadella, X. (2015b). El joc del 'rescat' en el procés constituent de l'esport contemporani a Catalunya (1920-1926). Aloma: Revista de Psicologia, Ciències de l'Educació i de l'Esport, 33(1), 7991. Recuperado de http://www.revistaaloma.net/index.php/aloma/article/view/245 
Brenan, G. (1962). El laberinto español. Paris: Ruedo Ibérico.

Burke, C. (2001). Hands-on history: towards a critique of the 'everyday'.

History of Education: Journal of the History of Education Society, 30(2), 191-201. doi: 10.1080/00467600010012463

Burke, C., y Grosvenor, I. (2007). The progressive image in the history of education: stories of two schools. Visual Studies, 22(2), 155-168.

Burke, P. (2005). Visto y no visto. El uso de la imagen como documento

histórico. Barcelona: Crítica.

Calvo, F. (2012). Escuela, espacio y poder. Estudios sobre la educación y territorio. Barcelona: UOC.

Campos, R. (1998). La teoría de la degeneración y la medicina social en España en el cambio de siglo. Llull: Revista de la Sociedad Española de Historia de las Ciencias y de las Técnicas, 21, 333-356.

Recuperado de

https://dialnet.unirioja.es/servlet/articulo?codigo $=893577$

Cardona, G. (1983). El poder militar en la España contemporánea hasta la guerra civil. Madrid: Siglo XXI Editores.

Clausewitz, K. (1984). De la guerra. Barcelona: Labor.

Climent, F. (1906). Educación de los niños. Barcelona: Sucesores de Manuel Soler.

Climent, F. (1912, 10 de diciembre). Educación militar. La Vanguardia, pp. 6-7.

Collelldemont, E. (coord.) (2014). Investigar la historia de la educación con imágenes. Vic: Eumogràfic: MUVIP.

Comas, F. (2010). Fotografía i història de l'educació. Educació i Història: Revista d'Història de l'Educació, 15, 11-17. Recuperado de http://www.raco.cat/index.php/EducacioHistoria/article/view/222927

Comas, F., March, M., y Sureda, B. (2010). Les Pràctiques educatives de l'escoltisme de Mallorca durant la dictadura franquista a través de les fotografies. Educació i Història: Revista d'Història de l'Educació, 15, 195-226. Recuperado de http://www.raco.cat/index.php/EducacioHistoria/article/view/222936

Cuesta, R. (2002). El código disciplinar de la historia escolar en España: Algunas idees para la explicación de la sociogénesis de una materia de enseñanza. Encounters on Education, 3, 27-41. Recuperado de https://dialnet.unirioja.es/servlet/articulo?codigo $=4683217$ 
De Bolòs, O., y Vilanou, C. (2005). Joventut, esport i religió: el moviment Muscular Christianity. Educació i Història: Revista d'Història de l'Educació, 7, 63-92. Recuperado de

http://www.raco.cat/index.php/EducacioHistoria/article/view/223069

De Freitas, T. (2015). Los fragmentos de la cultura escolar. Una mirada sobre las fotografías de las escuelas primarias públicas en el estado de Rio Grande do Sul/ Brasil (1924). En N. Padros y E. Collelldemont (Ed.), Actas del XVIII Coloquio de Historia de la Educación. Arte, literatura y educación. Vol. 2 (pp. 356-367). Vic: Universidad de Vic.

De Luelmo J. M. (2007). La historia al trasluz: Walter Benjamin y el concepto de imagen dialéctica. Escritura e imagen, 3, 163-176. Recuperado de http://revistas.ucm.es/index.php/ESIM/article/view/30252

De Unamuno, M. (1917, 16 de febrero). Juego Limpio. Nuevo Mundo, pp. 67.

Del Pozo, M. del M. (2000). Currículum e identidad nacional:

Regeneracionismos, nacionalismos y escuela pública (1890-1939).

Madrid: Biblioteca Nueva.

Del Pozo, M. del M. (2006). Imágenes e historia de la educación:

construcción, reconstrucción y representación de las prácticas escolares en el aula. Revista Historia de la Educación, 25, 291-315.

Recuperado de http://revistas.usal.es/index.php/0212-

0267/article/view/11183

Depaepe, M., y Henkens, B. (2000). The History of Education and the Challenge of the Visual. Paedagogica Historica, 36(1), 10-17. doi: doi: 10.1080/0030923000360101

E. (1990). La indústria tèxtil llanera de Sabadell, 1896-1925. Sabadell:

Gremi de Fabricants de Sabadell.

Dunning, E. (2003). El fenómeno Deportivo. Estudios sociológicos en torno al deporte, la violencia y la civilización. Barcelona: Paidotribo.

Dussel, I. (2013). The visual turn in the history of education: Four comments for a historiographical discussion. In T. S. Popkewitz (Ed.), Rethinking the History of Education (pp. 29-49). New York: Palgrave Macmillan.

Editorial (1912, 13 de julio). Festejos en Sabadell (Barcelona). La Hormiga de Oro, p. 40. 
Elias, J. (1907, 5 de octubre). Sport. Energías físicas. La Cataluña, p. 11. Elias, J. (1911, 7 y 14 de enero). La vida física". La Cataluña, pp. 29-30. Elias, J. (1913, 25 de diciembre). ¿Por qué hemos de hacer sport. Continuación. El Mundo Deportivo, p. 3.

Elias, J. (1914). Football asociación. Barcelona: Imp. R. Tobeña. Elias, N. (2010). El proceso de la civilización. Investigaciones sociogenéticas y psicogenéticas. Madrid: Fondo de Cultura Económica.

Fernández Enguita, M. (1990). La cara oculta de la escuela. Madrid: Siglo Veintiuno de España Editores.

Ferrer, A. (2012). Análisis de la reforma de Thomas Arnold a través del concepto de Función Moralizadora de Hernández Álvarez, JL (1996): El Deporte Moderno y la génesis del Movimiento Olímpico. Citius, Altius, Fortius, 5(1), 119-130. Recuperado de http://cdeporte.rediris.es/revcaf/Numeros de revista/Vol 5 n1/Vol5_n1_FerrerTorres.pdf

Florensa, J. (1992). Els esports als Escolapis de Catalunya (1883-1921). En XI Jornades d'Història de l'Educació als Països Catalans (pp. 277284). Reus: Centre de Lectura de Reus.

Foucault, M. (2003). Hay que defender la sociedad. Curso del Collège de France (1975-1976). Madrid: Akal.

Foucault, M. (2012). Vigilar y castigar. Nacimiento de la prisión. Madrid: Biblioteca Nueva.

Gamper, J. (1914). Prólogo. En J. Elías (aut.) Football asociación (pp. 9-18). Barcelona: Imp. R. Tobeña.

Gaskell, I. (1994). Historia de la imágenes. En P. Burke (ed.). Formas de hacer historia (pp. 209-239). Madrid: Alianza Universidad.

Giroux, H. (2013). Una pedagogía de la resistencia en la edad del capitalismo casino. Con-Ciencia Social, 17, 55-71. Recuperado de https://dialnet.unirioja.es/servlet/articulo?codigo $=4498716$

González Calleja, E. (1998). La razón de la fuerza: orden público, subversión y violencia política en la España de la Restauración (18751917). Madrid: CSIC.

Graham, G. (1913). Novismo tratado de Foot-Ball. Método práctico para jugar al foot-ball y apreciar la licitud y oportunidad de los jugadores. Barcelona: Ciencias y Letras. 
Hans [Gamper, H.] (1911, 1 de Agosto). La táctica en el foot-ball. Stadium, pp. I -II.

Hernández-Navarro, M. Á. (2011). Hacer visible el pasado. El artista como historiador (benjaminiano). En R. de la Villa (dir.), Sociedades en crisis: Europa y el concepto de estética (pp. 238-249). Madrid:

Ministerio de Cultura.

Hernández-Navarro, M. Á. (2012). Materializar el pasado: el artista como historiador (benjaminiano). Murcia: Micromegas.

Hinojosa, P. (2003). La joguina i el joc al retrat infantil holandès del segle XVII. Notes per una aproximació del simbolisme educatiu de la joguina i el joc en la pintura barroca. En La renovació pedagògica. Comunicacions de les XVI Jornades d'Història de l'Educació dels Països Catalans (pp. 533-550). Girona: CCG.

Hobsbawm, E. J. (2000). Naciones y nacionalismos desde 1780. Barcelona: Crítica.

Huguet, M. (2002). La memoria visual de la historia reciente. En M. G. Camarero (coord.). La mirada que habla (cine e ideologías). (pp. 822). Madrid: Akal.

Jensen, G. (2014). Cultura militar española. Modernistas, tradicionalistas y liberales. Madrid: Biblioteca Nueva.

Kirk, D. (2007). Con la escuela en el cuerpo, cuerpos escolarizados: La construcción de identidades inter/nacionales en la sociedad postdisciplinaria. Ágora para la educación física y el deporte, 4-5, 3956. Recuperado de https://dialnet.unirioja.es/servlet/articulo? codigo=2524859

Kirk, D. (2011). Las primeras formas de educación física en el Reino Unido: una narración visual". En P. Scharagrodsky (Comp.), La invención del "homo gymnasticus". Fragmentos históricos sobre la educación de los cuerpos en movimiento en Occidente (pp. 153-163). Buenos Aires: Prometeo.

Lara, E. L. (2005). La fotografía como documento histórico-artístico y etnográfico: una epistemología. Revista de antropología experimental, $5,1-28$.

Lomas, C. (coord.) (2011). Lecciones contra el olvido. Memoria de la educación y educación de la memoria. Memoria de la educación y educación de la memoria. Madrid: Octaedro. 


\section{Torrebadella - Militarización de la Educación Física Escolar}

Malheiro, J. M. (2015). Texto y contexto. La fotografía familiar en el estudio de la historia de la educación. En N. Padros y E. Collelldemont (Ed.), Actas del XVIII Coloquio de Historia de la Educación. Arte, literatura y educación. Vol. 2 (pp. 499-509). Vic: Universidad de Vic.

Martí, D. (1984). Per Catalunya i altres textos. Barcelona: La Magrana.

Masjuan, E. (2006). Medis obrers i innovació cultural a Sabadell (1900-

1939): L'altra aventura de la ciutat industrial. Bellaterra: Universitat

Autònoma de Barcelona.

Masjuan, E. (2009). Un héroe trágico del anarquismo español. Mateo Morral, 1979-1906. Barcelona: Icaria.

Moliner, A. (2000). Fèlix Sardà i Salvany y el integrismo en la Restauración. Barcelona: Universitat Autònoma de Barcelona

Moreno Martínez, P. L. (2015). Las misiones pedagógicas en Murcia. En N. Padros y E. Collelldemont (Ed.), Actas del XVIII Coloquio de Historia de la Educación. Arte, literatura y educación. Vol. 2 (pp. 393-408). Vic: Universidad de Vic.

Moreu, A. C. (2012). Educació, sexualitat i gènere. En C. Vilanou, y J. Planella, (Coord.), Cos, Esport i Pedagogia: històries i discursos (pp. 157-198). Barcelona: UOC.

Nerlich, M. (1990). Qu'est-ce un iconotexte? Réflexions sur le rapport textimage photographique dans 'La femme se découvre' d'Evelyne Sinnassamy. Alain Montandon (coord.), Iconotextes. Actes $d u$ colloque des 17-18 de mars, 1988 a l'Universté Blaise Pascal, Clermont-Ferrand (pp. 255-302). Paris: Ophrys.

Nóvoa, A. (2003). Textos, imágenes y recuerdos. En Th. S. Pokewitz, B. M. Franklin, y M. A. Pereyra (comps.), Historia Cultural y educación. Ensayos críticos sobre conocimiento y escolarización (pp. 61-87). Barcelona: Pomares.

Pantoja, A. (2007). La imagen como escritura. El discurso visual para la historia. Norba. Revista de historia, 20, 185-208. Recuperado de https://dialnet.unirioja.es/servlet/articulo?codigo $=2868047$

Perelman, M. (2014). La barbarie deportiva. Crítica de una plaga mundial. Barcelona: Virus Editorial.

Permanyer, L. (2008). El esplendor de la Barcelona burguesa. Barcelona: Angle.

Porcel, B. (1978). La revuelta permanente. Barcelona: Planeta. 
Pritchard, D. M. (2015). Deporte y democracia en la Atenas clásica. El Futuro del Pasado: revista electrónica de historia, 6, 69-86. doi: 10.14516/fdp.2015.006.001.002

Pujadas, X. (2012). Space and the Social Construction of the Modern City: The Urban Impact of Sports Involvement in Barcelona (1870-1923). International Journal of the History of Sport, 29(14), 1963-1980. doi: $10.1080 / 09523367.2012 .696348$

Rodríguez de las Heras, A. (2009). Metodología para el análisis de la fotografía histórica. Espacio, tiempo y forma. Serie V, Historia contemporánea, 21, 19-35.

Rodríguez de las Heras, A. (2010). L'ús pedagògic de la fotografia històrica. Educació i Història: Revista d'Historia de l'Educació, 15, 41-54.

Recuperado de

http://www.raco.cat/index.php/EducacioHistoria/article/view/222929

Rubio-Mayoral, J. L. (2009). Estudiantes Salesianos en la Real Maestranza de Sevilla (1957). Cabás, 2, 10.

Saladrigas, R. (1973). L'Escola del Mar i la renovació pedagògica a Catalunya. Barcelona: Edicions 62.

Sánchez-Valverde, C. (2009). La Junta de Protección de la Infancia de

Barcelona, 1908-1985. Aproximación y seguimiento histórico.

Barcelona: Generalitat de Catalunya.

Sanchidrián, C. (2011). El uso de imágenes en la investigación históricoeducativa. Revista de Investigación Educativa, 29(2), 295-309.

Sanz, M. (1913). Ensayo de una higiene deportiva o de los deportes ante la higiene. Madrid: Imp. "La Correspondencia Militar".

Soto, Á. (1989). El trabajo industrial en la España contemporánea, 18741936. Barcelona: Anthropos.

Torrebadella-Flix, X., y Olivera-Betrán, J. (2016). Institucionalización del fútbol en el ejército español (1919-1920). Orígenes del patrioterismo futbolístico nacional. El Futuro del Pasado, 7, 497-532. Recuperado de

http://www.elfuturodelpasado.com/ojs/index.php/FdP/article/view/261 Torrebadella-Flix, X., y Nomdedeu-Rull, A. (2013). Foot-ball, futbol, balompié... Los inicios de la adaptación del vocabulario deportivo de origen anglosajón. RICYDE. Revista Internacional de Ciencias del Deporte, 31, 5-22. doi: 10.5232/ricyde2013.03101 
Torrebadella-Flix, X., y Nomdedeu-Rull, A. (2015). Los primeros libros de fútbol publicados en España (1900-1919). Revista General de Información y Documentación, 25(1), 113-139. doi:

http://dx.doi.org/10.5209/rev_RGID.2015.v25.n1.48985

Torrebadella, X. (2012). Orígenes del fútbol en Barcelona (1892-1903).

RICYDE. Revista Internacional de Ciencias del Deporte, 27, 80-102. Torrebadella, X. (2014a). Josep Clos i Peig, gimnasiarca i propagador de l'educació física i l'esport a Sabadell (1871-1913). Arraona, 34, 174197.

Torrebadella, X. (2014b). La educación física comparada en España (18061936). Historia Social y de la Educación, 3(1), 25-53. doi:

http://dx.doi.org/10.4471/hse.2014.02

Torrebadella, X. (2014c). Regeneracionismo e impacto de la crisis de 1898 en la educación física y el deporte español. Arbor, 190(769) a173. doi: http://dx.doi.org/10.3989/arbor.2014.769n5012

Torrebadella, X. (2015a). Los batallones infantiles en la educación física española (1890-1931). ODEP. Revista Observatorio del Deporte, 1(1), 32-70.

Torrebadella, X. (2015b). Orígenes de la educación física en las escuelas públicas: El caso particular del Ayuntamiento de Barcelona durante el siglo XIX. Cabás, 13, 38-64.

Torrebadella, X. (2016a). España, regeneracionismo y deporte durante la I Guerra Mundial. Athenea Digital. Revista de Pensamiento e Investigación Social, 16(1), 237-261.

doi:http://dx.doi.org/10.5565/rev/athenea.1501

Torrebadella, X. (2016b). Francisco Ferrer Guardia, postmoderno avanzado y precursor de la educación física crítica. Análisis y reflexión para un giro didáctico. Educar, 52(1), 169-191. doi:

http://dx.doi.org/10.5565/rev/educar.756.

Torrebadella, X. (2016c). La bibliografía gimnástica y deportiva de la educación física en el ejército español (1808-1919). Textos en contexto social. Revista Universitaria de Historia Militar, 5(9), 173192. Recuperado de https://ddd.uab.cat/pub/artpub/2016/157709/RUHM_1.pdf 
Torres, A. (2006). Por una investigación desde el margen. En A. Jiménez y

A. Torres (comp.), La práctica investigativa en ciencias sociales ( $\mathrm{pp}$.

61-79). Bogota: Universidad Pedagógica Nacional.

Turin, Y. (1967). La educación y la escuela en España de 1874 a 1902.

Liberalismo y Tradición. Madrid: Aguilar.

Ucelay-Da Cal, E. (2003). El imperialismo catalán. Prat de la Riba, Cambó, D'Ors y la conquista moral de España. Barcelona: Edhasa.

Valdés, A. F. (2012). Walter Benjamin: una historia desde la fotografía. Logos, 21, 45-65.

Valserra, F. (1944). Historia del deporte. Barcelona: Ed. Plus-Ultra.

Varela, J. (1986). Aproximación genealógica a la moderna percepción social de los niños. Revista de Educación, 281, 155-175.

Veblen, T. (2008). Teoría de la clase ociosa. Madrid: Alianza Editorial.

Vicente, M. (2004). Cuerpo y contracuerpo: la historicidad de las producciones corporales y el sentido de la Educación Física. Educación Física y Ciencia, 7, 68-86.

Vicente, M. (2010). La educación física e ideología. Creencias pedagógicas y dominación cultural en las enseñanzas escolares del cuerpo. Retos: Nuevas tendencias de la Educación Física, Deporte y Recreación, 17, 76-85. Recuperado de http://www.redalyc.org/articulo.oa?id=345732283016

Vick, M. (2009). Re-imagining teachers' work: photographs of Blackfriars School, Sydney, 1913-1923 as representations of an educational alternative. History of Education Review, 38(2), 82-93. Doi: http://dx.doi.org/10.1108/08198691200900015

Viñao, A. (2005). La memoria escolar: restos, huellas, recuerdos y olvidos. En AA.VV., Homenaje al profesor Alfonso Capitán (pp. 739-758). Murcia: Universidad de Murcia.

Zemelman, H. (2003a). Los horizontes de la razón: uso crítico de la teoría. I Dialéctica y apropiación del presente. Las funciones de la totalidad. Barcelona: Anthropos.

Zemelman, H. (2003b). Los horizontes de la razón: uso crítico de la teoría. II Historia y necesidad de la utopía. Barcelona: Anthropos. 
108 Torrebadella - Militarización de la Educación Física Escolar

Xavier Torrebadella: Profesor del Departamento de Didáctica de la Expresión Musical, Plástica y Corporal. Universitat Autònoma de Barcelona (Spain)

https://orcid.org/0000-0002-1922-6785

Contact Address: xtorreba@gmail.com 